\title{
Sociobiology
}

RESEARCH ARTICLE - ANTS

\section{Wood Ant (Formica polyctena) Services and Disservices in a Danish Apple Plantation}

\author{
J OfFEnBERG, JS NIELSEN, C DAMgAARD
}

Aarhus University, Silkeborg, Denmark

\section{Article History \\ Edited by \\ Gilberto M. M. Santos, UEFS, Brazil \\ Received 22 November 2018 \\ Initial acceptance 15 May 2019 \\ Final acceptance 15 May 2019 \\ Publication date 20 August 2019}

\section{Keywords}

Integrated pest management, winter moth, plant pathogens, fertilization, ant-aphid mutualism, apple diseases.

\section{Corresponding author}

Joachim Offenberg

Department of Bioscience

Aarhus University

Vejlsøvej 25, DK-8600 Silkeborg.

E-Mail: joaf@bios.au.dk

\begin{abstract}
Ants possess properties that can be used to optimize plant production in agricultural systems. Ant services can be herbivore and pathogen protection and fertilization of their plant partners. They may, however, also harm plants by facilitating antattended herbivorous homopterans. To assess whether wood ants can be used in IPM-systems to improve apple production, we transplanted wood ants into a Danish apple plantation and tested whether ants (i) reduced the number of herbivores, (ii) led to higher amounts of leaf nutrients, (iii) controlled apple pathogens, (iv) increased homopteran abundance and (iv) whether these effects affected apple yields. During a two year study, we found that the wood ants significantly reduced the numbers of winter moth larvae, increased magnesium content in apple leaves (but did not affect 10 other nutrients), reduced the number of apples infected with apple brown rot and apple scab (on one apple variety) and increased aphid infections. In the first year, this led to higher apple production on ant trees, whereas ants had no effect on yields in the second year. It was evident that ants provided both services and disservices. If mutualistic ant-homopteran interactions can be disrupted, this would favor plant growth and open for the use of wood ants in sustainable plant management. We discuss how this may be accomplished. Alternatively, ants may be used short term to knock down pest outbreaks (before building up homopteran populations) or used in crops that do not host ant-attended homopterans.
\end{abstract}

\section{Introduction}

The demand for ecofriendly and sustainable fruit production without pesticide residues is increasing. To achieve such production, new tools are needed to substitute current methods that are mainly based on synthetic chemicals (pesticides and artificial fertilizers). One way is to develop integrated pest management (IPM) based on biological rather than chemical solutions.

Due to their high numbers and being organized as a superorganism, ants can provide a number of services for commercial crops and plants in general. First, ants may prey on or deter arthropod pests (Way \& Khoo, 1992; Offenberg, 2014). This ant service is widely recognized. Secondly, ants may provide nutrients to their host plants by depositing waste materials. This is well known from ant-plants living in close association with ants (Rico-Gray \& Oliveira, 2007), but recently it has been suggested that nutritional services may also take place in less specialized ant-plant partnerships, where ants do not nest in domatia, yet deposit fecal spots on plant tissue. These fecal spots may contain important nutrients that can be taken up directly by plant leaves (Vidkjær et al., 2016; Pinkalski et al., 2018). In addition, ants may enrich soils around plant roots with nutrients that originate from their waste deposits (Folgarait, 1998; Frouz et al., 2008; Wagner \& Fleur Nicklen, 2010). A potential second service from ants to plants may therefore be nutrient provisioning. Lastly, ants may also provide plant services by reducing plant pathogen incidence. A number of studies have documented reduced plant pathogen incidence on host plants attended by ants compared to ant-free control plants. In a review of studies examining ant-plant-pathogen interactions, it was found that 
13 ant species were able to control at least 13 fungal and bacterial plant pathogens on 11 different plant species (J. Offenberg, unpublished data - submitted to Oikos). There can be several mechanisms behind pathogen protection. For example, ants may inhibit plant pathogens by eating fungal spores (Letourneau, 1998; Thornham et al., 2011), excreting antibiotics (Peng \& Christian, 2005; Gonzalez-Teuber et al., 2014) or by deterring diseases vectors (Letourneau, 1998; Roux et al., 2011). Taken together, the provision of these three types of services may lead to highly effective ant-based biocontrol programs. In some crops, ants have been shown to be more efficient than conventional control based on synthetic pesticides, and at lower costs (Offenberg, 2015).

However, not all ant activities are beneficial to plants. Many ant species attend harmful honeydew-producing homopterans that feed on plant sap and can act as disease vectors (Delabie, 2001). As ants improve hygiene and protect homopteran partners against natural enemies, homopteran populations may increase in numbers when ant-attended. Therefore, ants can also exert indirect negative effects on plants (Wäckers et al., 2017). A number of research activities aimed at developing techniques to disrupt ant-homopteran symbioses in commercial crops illustrate the importance of this disservice to agriculture. Methods include blocking of ants' access to plant canopies by placing sticky barriers around tree trunks or by providing sugar to ants via artificial feeders (Nagy et al., 2013; Nagy et al., 2015; Wäckers et al., 2017). The latter will provide ants with a carbohydrate source that is an alternative to the honeydew produced by the attended homopterans. The presence of this alternative may alter ant behavior so they neglect their homopteran partners (Nagy et al., 2015; Wäckers et al., 2017) or even start to prey on them (Way, 1954; Offenberg, 2001). If ant-homopteran mutualism can be disrupted, beneficial ant services can be harvested without accompanying indirect negative effects.

To assess the potential of an ant species as a biocontrol agent, it is thus important to map its services and disservices and to assess its combined net effect on plant performance. Wood ants (Formica spp.) have shown potential as biocontrol agents in temperate open field crops (Way \& Khoo, 1992; Nielsen et al., 2018). Here, we present a study where we evaluated the services and disservices provided by wood ants (Formica polyctena) that were transplanted into a Danish apple plantation to control winter moth larvae (Operophtera brumata). Specifically, we tested the hypotheses that wood ants can (i) reduce herbivore abundance, (ii) fertilize host plants with nutrients, (iii) control plant pathogens, (iv) increase homopteran abundance and, lastly, that they via these effects can, (v) affect apple yields.

\section{Methods}

Study site

The experiment was conducted in an organic apple orchard located near Tirstrup in Denmark (56 $16^{\circ} 36.9^{\prime \prime} \mathrm{N}$, $10^{\circ} 41^{\prime} 28.1$ 'E) in 2015 and 2016. The total size of the orchard was 1.3 ha and included approximately 3000 sevenyear-old row-arranged trees $(3.5 \mathrm{~m}$ between rows and $1 \mathrm{~m}$ between trees within rows) of 11 varieties (though not all varieties were covered in our studies.). A two-meter wide vegetation buffer strip, consisting of non-hoed herbs and grasses, and two machinery tracks divided the 9 rows in two, with 4 rows to the west and 5 rows to the east. Two additional vegetation buffer strips framed the study area to the west and the east. The main herbs and grasses were meadow-grass (Poa sp.), dandelion (Taraxacum sp.), orchard grass (Dactylis glomerata), couch grass (Elytrigia repens), common tansy (Tanacetum vulgare), cow parsley (Anthriscus sylvestris) and creeping thistle (Cirsium arvense). Drainpipes drained the area, but standing water was occasionally found in the lower parts of the plantation from fall to spring.

\section{First year study - 2015}

The experimental area used during the first year included 0.25 ha of the plantation covering nine rows of trees, each row holding one of five different varieties (Holsteiner Cox, Alkmene, Collina, Angold and Resista). Trees that were severely damaged or recently re-grafted were excluded, and thus the total number of trees included in the study was 411 . On 27-4 2015, eight wood ant (F. polyctena) mound fragments were transplanted into this area. The fragments were made from one large mound collected at Løvenholm forest the same day by splitting the large mound into eight equally sized parts and providing each fragment with several ovipositing ant queens (nests are polygynous). The size of each fragment was approximately $90 \mathrm{~L}$, and the spacing between them was $15-20 \mathrm{~m}$, with four mounds placed in the central vegetation strip and two mounds in each of the two outer strips. In the first week after the transplantation, ants were fed with sugar dough (Ambrosia ${ }^{\circledR}, 85 \%$ sucrose, Nordzucker) and water next to the mounds. After this, they were only offered sugar from feeders mounted on selected apple trees (sugar trees). Feeders were made from a $50 \mathrm{ml}$ centrifuge tube that was filled with $60-80 \mathrm{~g}$ sugar dough. Five holes $(\varnothing=4 \mathrm{~mm})$ were made in the lid of each tube to allow ants access to the sugar and keep out larger animals. For more details on the wood ant transplantations and maps of the plantation, see Nielsen et al. (2018). One sugar feeder was mounted with a metal wire to each of 34 trees at a height of approximately $1.2 \mathrm{~m}$. Trees with sugar feeders were selected by dividing each row of trees into four equally long segments, except one row with few trees that was divided into two segments. Within each segment, one tree was randomly selected as a sugar tree. The 34 sugar trees were each paired with a neighboring control tree of similar appearance. Ants were excluded from control trees by a sticky barrier (OecoTak A5, Oecos) applied around the trunk of the tree. All remaining trees in the plot were accessible to ants, but without sugar feeders. This design resulted in trees with variable numbers of ants, including trees without any ants. 
On all the 411 trees in the plot, an ant density index was assessed for each tree. Due to the high number of trees, ant densities were indexed as (i) no ants $=$ index value 0 , (ii) $1-10$ ants $=$ index value 1 or (iii) more than 10 ants per tree $=$ index value 2 , based on a 20 -second inspection of each tree. This was done six times during the season $(13-5,22-5,4-6,11-$ 6, 21-6, and 23-7). On four dates (4-6, 11-6, 21-6 and 23-7), the presence of aphids on each tree was assessed. The presence of at least one aphid colony on a tree was scored with the value 1 , the absence of aphid colonies as 0 , and the average value of the four dates was calculated for each tree. On 3-9, the number of apples was counted on each tree. During analyses, we tested the effect of the highest ant index value recorded on each tree during the six samplings (treated as a categorical variable) on the average aphid index and on the yield of apples (using the average ant index instead of the maximum ant index led to qualitatively similar results).

\section{Second year study - 2016}

In the second year, we worked in another part of the plantation, approximately 50 meters south of the plot used in 2015. In April, we transplanted four $F$. polyctena ant mound fragments, each of about $180 \mathrm{~L}$, into an approximately 0.11 hectare plot. Two fragments were placed in each of the central and the eastern vegetation strips bordering the five eastern rows of apple trees. The four fragments were formed from one large mound collected from Løvenholm forest, as described above (Nielsen et al., 2018). Mound material with ants was placed on the soil in the vegetation strips 3-4 meters from the nearest rows of apple trees. Spacing between the two ant mounds on each side was approximately $20 \mathrm{~m}$. The middle row of the five apple rows was not assessed, as trees in this row had been grafted the previous year. In each of the four remaining rows (with the varieties Resista, Holsteiner Cox, Collina and Alkmene, respectively), 10 randomly selected trees were ant-excluded by providing them with sticky barriers as described above (ant-free trees), and another 10 trees were mounted with sugar feeders (sugar trees). We used the same type of feeders as in 2015 , except we used a $40 \%$ organic sucrose solution plugged with a cotton plug that the ants could drink from (as we realized that the ants preferred sugar dissolved in water to sugar dough). All other trees within the four rows were freely accessible to ants, but without sugar feeders (the latter two types of trees commonly referred to as ant-trees). In the plot, there were between 31 and 37 trees of each variety.

On all trees, we assessed the abundance of winter moth larvae, aphids, apples and fungal diseases and, lastly, we analyzed leaf chemistry on a subsample of trees to test whether ants fertilized the apple trees. On May 10, the number of Operophtera brumata larvae was counted on each tree, and on July 28 the total number of shots and the number of shoots infested by green apple aphids (Aphis pomi) were counted (we did not observe any rosy apple aphids, Dysaphis plantaginea). In August, we sampled 20 leaves from each of the trees with sugar feeders and from each of the neighboring control trees without ants. Leaves were sampled from the middle positions of shoots from the same year and dried at 60 degree Celsius for 24 hours. The dried leaves were subsequently analyzed for their content of macro and micronutrients $(\mathrm{N}, \mathrm{P}, \mathrm{K}, \mathrm{Ca}, \mathrm{Mg}$, $\mathrm{S}, \mathrm{Fe}, \mathrm{Mn}, \mathrm{Zn}, \mathrm{Cu}$ and $\mathrm{B}$ ). During harvest, we counted the number of apples infected with brown rot (Monilia fructigena) and apple scab as well as the number of first quality apples (eating apples; defined as apples without any damage, except up to three small scab marks) and second quality apples (juice apples; defined as apples with damage marks, but without holes in the apple skin). An apple was considered infected with scab if the apple contained more than three brown spots caused by Venturia inaequalis, as this damage level means that the apple cannot be sold as an eating apple. Disease incidence and apple yields were assessed on all trees. Larval numbers, the proportion of aphid-infested shoots, yields of first and second quality apples, the proportion of apples infected with the two fungal diseases and leaf nutrients were subsequently compared between treatments.

The sugar feeders on the sugar trees were assumed not to affect ant behavior, but only ant numbers (used to attract ants). There is no reason to believe ants behaved differently on trees with and without sugar feeders, as the ants foraging on both types of trees belonged to the same colony and, thus, were in the same nutritional condition (as ants perform collective foraging).

\section{Statistical analyses}

The effects of ants (maximum ant index value for the 2015 data and treatment [ants vs no ants] for the 2016 data) were tested using approximate Bayesian methods with the $\mathrm{R}$ package R-INLA (Rue et al., 2009). The response variables were either count data (apple yields, winter moth larvae), frequency data (aphid infections in 2015 and 2016, brown rot and scab infections), or concentrations (magnesium content). The count data were assumed to be distributed according to a zero-inflated negative binomial distribution, in which the additional zero values are generated by an independent process, and the log-transformed mean is modelled by a linear model of the fixed factors. The frequency data were assumed to be distributed according to a beta-binomial distribution, in which the logit-transformed mean probability is modelled by a linear model of the fixed factors. The concentrations were assumed to be normally distributed, where the mean is modelled by a linear model of the fixed factors.

\section{Results}

First year study

The presence of aphids on the trees was significantly affected by the maximum ant index value registered during the season, with a higher likelihood of aphid presence on trees 
with more ants and without any aphids on trees where no ants were found (Table 1; Figure 1). This effect was consistent for all varieties. Overall (across varieties and treatments), the highest number of trees infected with aphids was $7 \%$ during the third survey (21-6).

Apple yields were also significantly affected by the maximum ant index value, with all varieties showing higher yields on trees with more than 10 ants compared to trees with less than 10 ants (Table 1; Figure 2). When pooling all varieties, there was a 2.4-fold increase in apple yield on trees with more than 10 ants compared to trees with less or no ants. It should be noted, though, that yields were very low this year with an overall average of only $2.9( \pm 0.27 \mathrm{SE})$ apples per tree. Table 1 shows the pooled effect with all varieties included. In this analysis, there was one significant interaction showing that the lowest ant index value of zero ants (index value 0 ) differed from the highest index value of $>10$ ants (index value 2) on Collina trees. If, based on this single interaction, varieties were analyzed separately, a significant effect of ant presence was only seen on Alkmene and a close to significant effect on Resista. The lack of significance on the remaining varieties was probably due to the lowered sample sizes when varieties were analyzed separately. It should be noted, though, that the trend for higher yields with more ants is consistent across varieties (Figure 2).
Aphid infection rate 2015

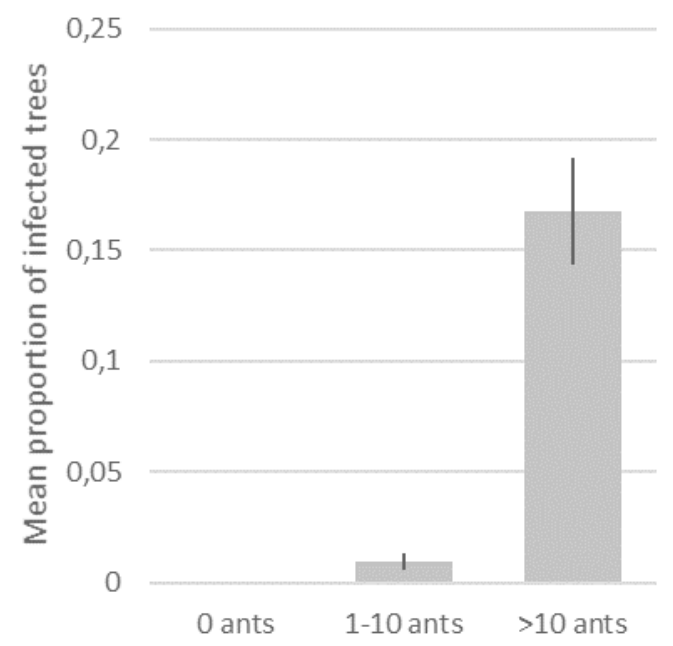

Fig 1. The mean $( \pm \mathrm{SE})$ proportion of trees infested with aphids in 2015 by maximum ant index. $\mathrm{N}=141,179,91$ trees, respectively for $0,1-10$ and $>10$ ants.

\section{Second year study}

The number of $O$. brumata larvae was significantly reduced by ant presence, and this effect was consistent across all varieties (Table 1; Figure 3) with 4.4-fold more larvae found on control trees compared to trees with ants. Again this year,

Table 1. The marginal posterior distributions of the effects of the fixed factors summarized by their $2.5 \%, 5 \%, 50 \%, 95 \%$ and $97.5 \%$ percentiles. The effects of ants on responses marked with two asterisks are considered two-tailed significant at the 5\% level, as the quantiles within each response do not overlap 0 , and responses marked with one asterisk are considered one-tailed significant, as only the upper $97.5 \%$ or the lower $2.5 \%$ overlap 0 .

\begin{tabular}{|c|c|c|c|c|c|c|c|c|c|}
\hline Response & Ant abundance & Variety & Mean & SD & $\begin{array}{c}2.5 \% \\
\text { Quantile }\end{array}$ & $\begin{array}{c}5 \% \\
\text { Quantile }\end{array}$ & $\begin{array}{c}50 \% \\
\text { Quantile } \\
\end{array}$ & $\begin{array}{c}95 \% \\
\text { Quantile }\end{array}$ & $\begin{array}{c}97.5 \% \\
\text { Quantile }\end{array}$ \\
\hline \multicolumn{10}{|l|}{2015} \\
\hline \multirow[t]{2}{*}{ Aphids** } & $\begin{array}{l}\text { Max ant index }(1-10 \text { ants minus } \\
\left.>10 \text { ants category }{ }^{1}\right)\end{array}$ & All varieties & -0.66 & 0.29 & -1.22 & -1.13 & -0.66 & -0.18 & -0.082 \\
\hline & $\begin{array}{l}\text { Max ant index ( } 0 \text { ants minus } \\
>10 \text { ants category) }\end{array}$ & All varieties & -0.66 & 0.26 & -1.16 & -1.08 & -0.67 & -0.22 & -0.13 \\
\hline \multirow[t]{2}{*}{ Apple yield** } & $\begin{array}{l}\text { Max ant index ( } 1-10 \text { ants minus } \\
>10 \text { ants category) }\end{array}$ & All varieties & -0.85 & 0.43 & -1.7 & -1.56 & -0.84 & -0.15 & -0.016 \\
\hline & $\begin{array}{l}\text { Max ant index ( } 0 \text { ants minus } \\
>10 \text { ants category) }\end{array}$ & All varieties & -2.13 & 0.43 & -2.99 & -2.85 & -2.13 & -1.44 & -1.32 \\
\hline \multicolumn{10}{|l|}{2016} \\
\hline Larvae $^{* *}$ & Treatment (no ants minus ants ${ }^{2}$ ) & All varieties & 2.18 & 1.11 & 0.26 & 0.53 & 2.09 & 4.17 & 4.62 \\
\hline Aphids** & Treatment (no ants minus ants) & All varieties & -1.27 & 0.42 & -2.12 & -1.98 & -1.27 & -0.6 & -0.47 \\
\hline Mg content* & Treatment (no ants minus ants) & All varieties & -0.0089 & 0.0045 & -0.018 & -0.016 & -0.0089 & -0.0014 & 0.0001 \\
\hline $\begin{array}{l}\text { Apples w } \\
\text { brown rot }\end{array}$ & Treatment (no ants minus ants) & $\begin{array}{l}\text { Alkmene \& } \\
\text { Collina }\end{array}$ & 0.6 & 0.31 & -0.042 & 0.067 & 0.6 & 1.1 & 1.2 \\
\hline Apples w scab* & Treatment (no ants minus ants) & Holsteiner Cox & 1.57 & 0.87 & -0.026 & 0.21 & 1.52 & 3.07 & 3.4 \\
\hline $\begin{array}{l}\text { First quality } \\
\text { apples }^{\text {NS }}\end{array}$ & Treatment (no ants minus ants) & All varieties & -0.063 & 0.29 & -0.64 & -0.54 & -0.062 & 0.41 & 0.5 \\
\hline $\begin{array}{l}\text { Second quality } \\
\text { apples }^{N S}\end{array}$ & Treatment (no ants minus ants) & All varieties & 0.12 & 0.23 & -0.35 & -0.27 & 0.12 & 0.5 & 0.58 \\
\hline
\end{tabular}

${ }^{1}$ The high level ant index (>10 ants) is included in the intercept.

${ }^{2}$ The treatment with ants is included in the intercept. 


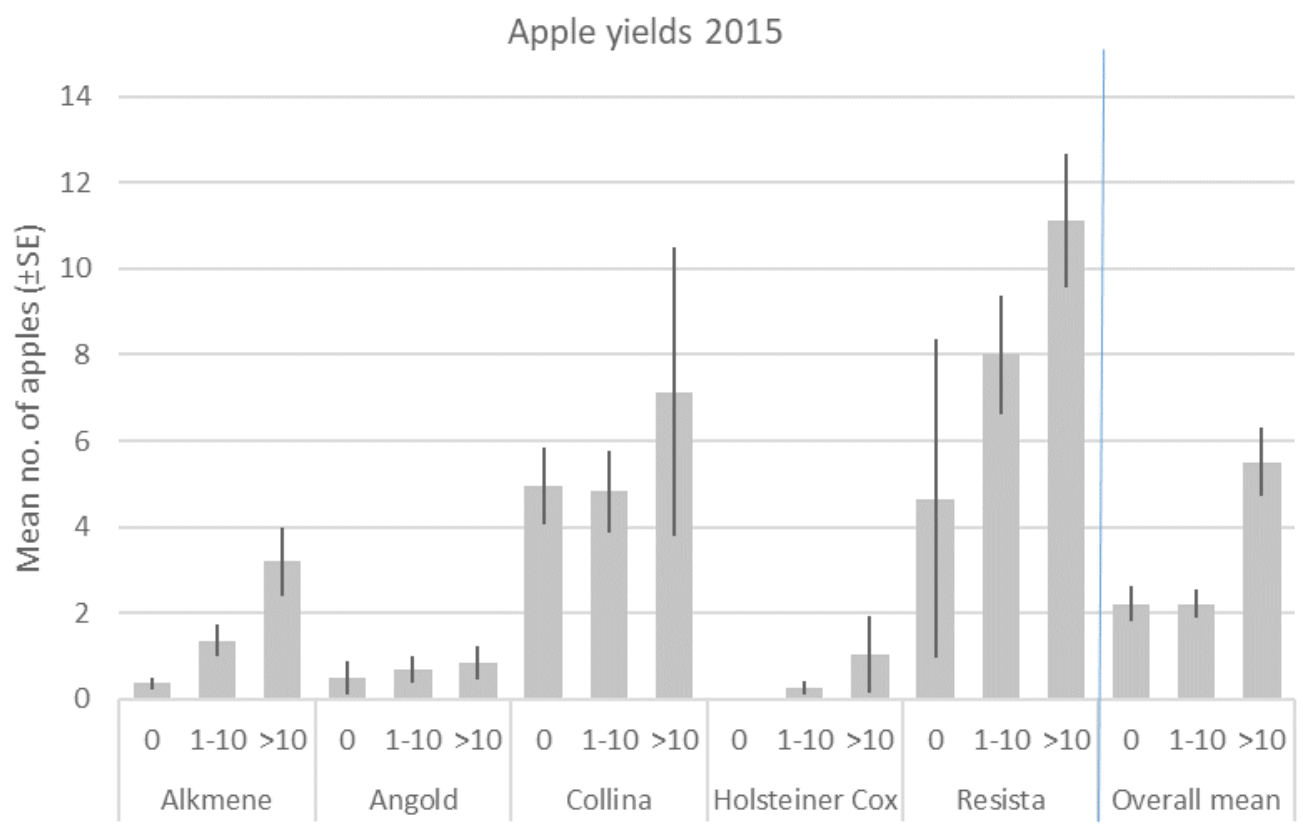

Fig 2. Mean $( \pm \mathrm{SE})$ number of apples by maximum ant index and apple variety. Last group shows the overall mean of all varieties. $\mathrm{N}=$ Alkmene 55, 30, 20; Angold 8, 23, 14; Collina 55, 40, 7; Holsteiner Cox 20, 70, 18; Resista 3, 16, 32; overall mean 141, 179, 91 trees, respectively, for 0,1-10 and >10 ants.

aphids were promoted by ant presence, as the average proportion of infested shoots was 2.5-fold higher on ant trees compared to the controls (Table 1; Figure 4). The total proportion of trees infected with aphids was $89 \%$. Regarding leaf nutrients, most nutrients were unaffected by ant presence, except magnesium. Magnesium content was 5\%, and significantly higher in leaves from ant trees compared to the controls (Table 1 and Figure 5). Interestingly, fungal disease incidence was also affected by ant presence. Only the varieties Alkmene and Collina were infected with brown rot. On these two varieties, brown rot incidence was 2.3-fold higher on control trees compared to trees with ants, and this difference was statistically significant (Table 1 and Figure 6). All apple varieties were infected with apple scab, but in this

\section{Winter moth larvae 2016}

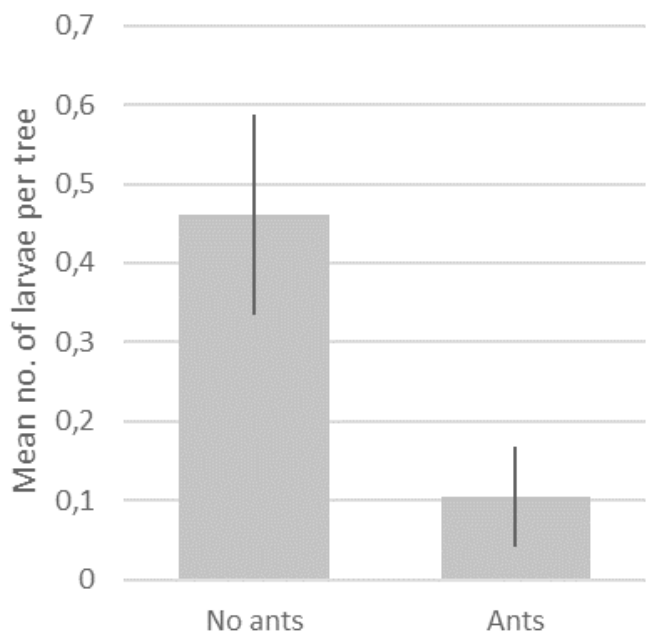

Fig 3. Mean $( \pm \mathrm{SE})$ number of winter moth larvae (Operophtera brumata) per tree by treatment in $2016 . \mathrm{N}=96$ trees with ants and 39 trees without ants. case ant presence only led to a significant reduction on Holsteiner Cox (Table 1, Figure 7), though similar trends were observed on Alkmene and Collina. Only Resista, which is partly resistant to scab, showed a weak and non-significant trend in the opposite direction (Figure 7). On Holsteiner Cox, the proportion of scabinfected apples was 11.4-fold higher on control trees compared to ant trees (Table 1 and Figure 7). There was no significant net effect of these services and disservices, as apple yields in 2016 were unaffected by ant presence; neither the number of first or second quality apples differed between treatments (Table 1). Total yield was $32.8 \pm 1.86 \mathrm{SE}$ apples per tree in 2016, which was more than 11 -fold higher than the 2015 yield $(2.9 \pm 0.27 \mathrm{SE}$ apples per tree).

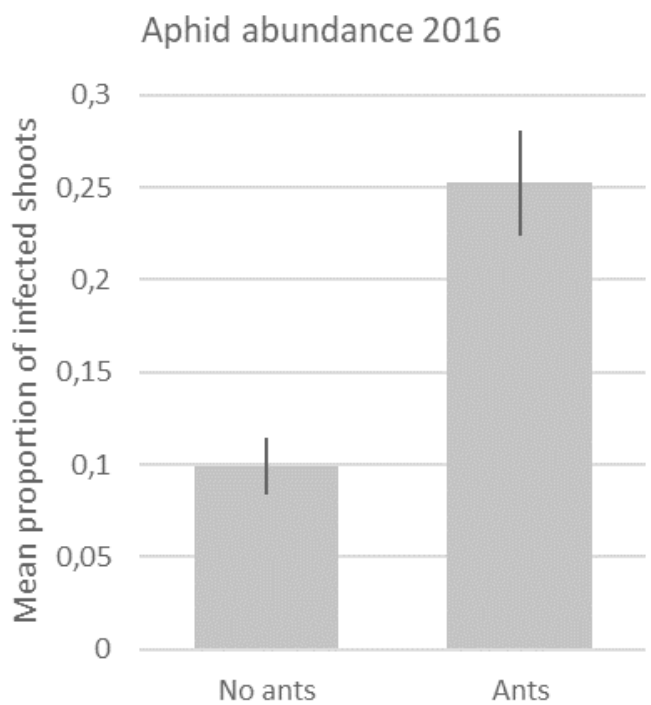

Fig 4. Mean $( \pm \mathrm{SE})$ proportion of aphid (Aphis pomi) infested shoots per tree by treatment in $2016 . \mathrm{N}=96$ trees with ants and 39 trees without ants. 


\section{Discussion}

It was evident that wood ants provided both services and disservices in the apple plantation. Ants reduced the number of winter moth larvae and the incidence of two fungal diseases and increased Mg levels in the leaves of apple trees. During the first year, they also increased apple yield. On the other hand, ants also led to significantly more aphids on the apple trees.

\section{Magnesium content in apple leaves}

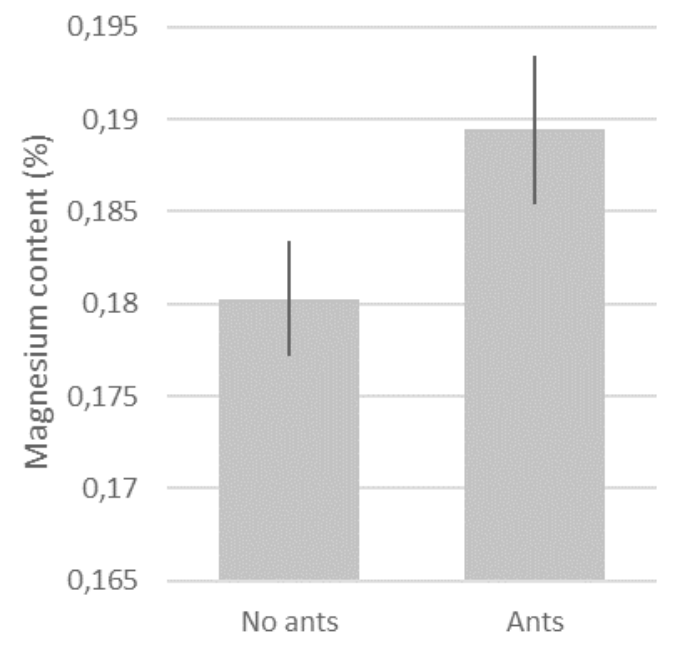

Fig 5. Mean $( \pm \mathrm{SE})$ magnesium content (\%) in apple leaves by treatment. $\mathrm{N}=35$ trees with ants and 37 trees without ants.
These results suggest that wood ants have the potential to be utilized as biocontrol agents in plantations if their mutualistic interaction with aphids can be broken or if they are used in systems that are not attacked by ant attended aphid species. Alternatively, wood ants may be used curatively on a shortterm basis to combat pest outbreaks (e.g. winter moth larvae) before being removed from the plantation again in order to avoid subsequent build up in aphid numbers.

\section{Brown rot infection rate 2016}

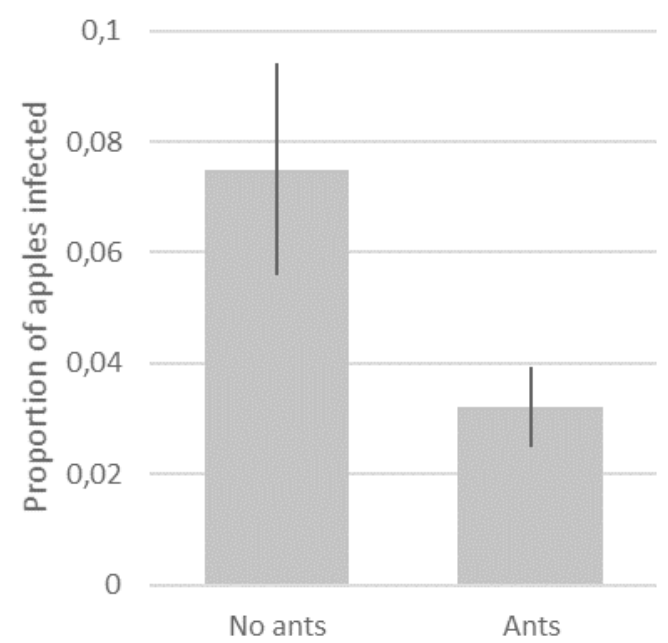

Fig 6. Mean $( \pm \mathrm{SE})$ proportion of apples infected with brown rot (Monilia fructigena) by treatment. Only apples on Alkmene and Collina are included, as the two other varieties were not infected by this pathogen. $\mathrm{N}=49$ trees with ants and 19 trees without ants.

\section{Scab infection 2016}

\section{0,7}

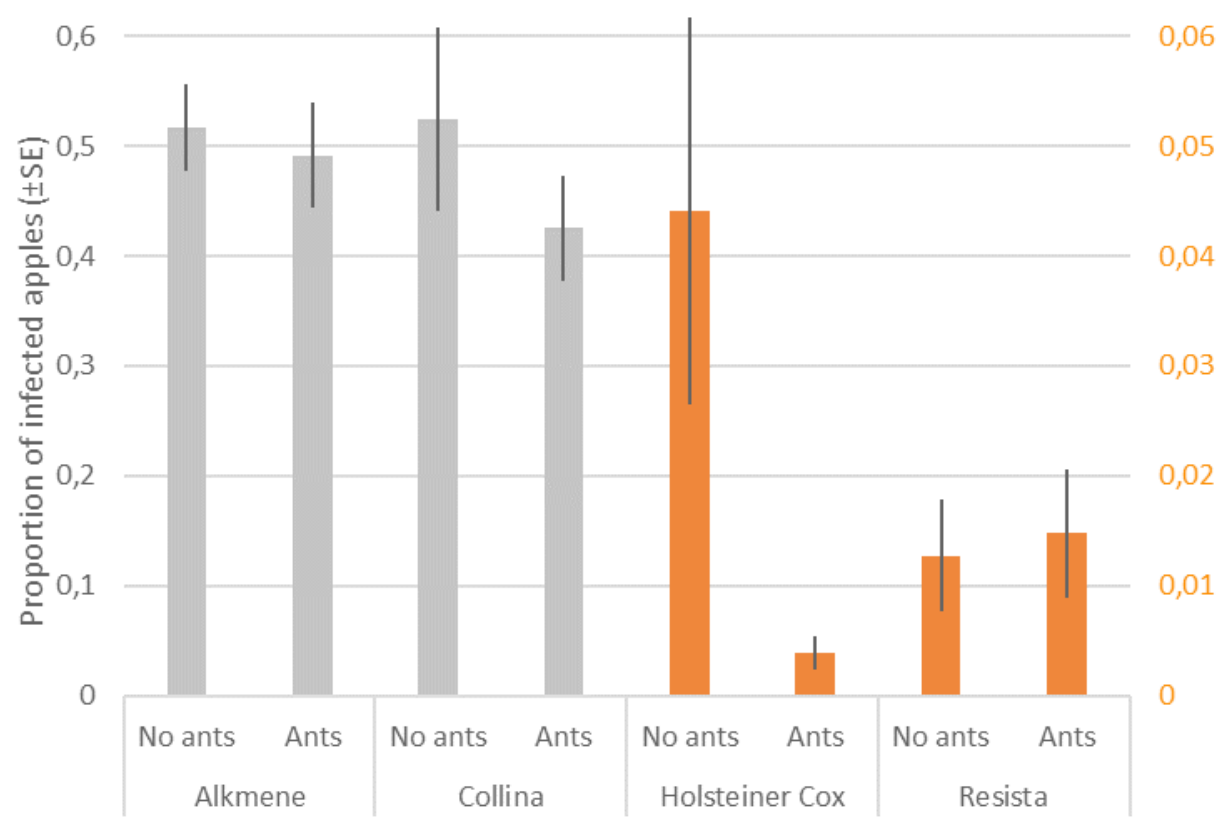

Fig 7. Mean $( \pm \mathrm{SE})$ proportion of apples infected by scab by treatment and variety. Note the difference in scale between the left (Alkmene and Collina) and right (Holsteiner Cox and Resista) Y-axes. N (trees) for no-ants and ant treatments, respectively: Alkmene 9, 21; Collina 10, 28; Holsteiner Cox 10, 21; Resista 10, 26. 
The anti-herbivore role played by ants is not surprising, as wood ants ( $F$. rufa) are known to prey on winter moth larvae in forests (Skinner \& Whittaker, 1981) as well as on a number of other pest insects, especially high-density epidemic species (Way \& Khoo, 1992 and references therein). Similarly to the data reported here, we showed in an earlier study that $F$. polyctena was able to reduce the number of winter moth larvae in the same apple plantation during the 2015 season on Angold and Holsteiner cox (Nielsen et al., 2018). Together, these results suggest that wood ants can be used to control winter moths in plantations.

In addition, aphids were highly affected by ant presence, but in this case positively. Trees with more ants were more likely to host aphids and showed a higher proportion of aphid infected shoots (Table 1). These effects were pronounced, with ant trees experiencing several fold higher infection risks in 2015 (Figure 2) and with a 2.4-fold higher proportion of shoots infected in 2016 (Figure 5). This positive effect of ants on aphids was evident despite the fact that ants were fed with sugar in both years. This is surprising, as other studies have shown that sugar fed ants (Lasius niger and L. grandis) are likely to decrease aphid tending and in this way open up for opportunities for aphid natural enemies to control the aphid populations (Nagy et al., 2013; Nagy et al., 2015; Wäckers et al., 2017). In other cases, ants (Oecophylla smaragdina and L. niger) may even start to prey on their aphid partners to utilize them as a source of protein when they are given alternative sources of sugar (Way, 1954; Offenberg, 2001). This may suggest that wood ants are more difficult to distract from aphid attendance than other ant species. We infer that more attractive sugar solutions than sucrose (at 85 and $40 \%$ ) are required to distract wood ants from attending their aphid partners. It is known that different sugars and e.g. the addition of proteins or free amino acids to sugar solutions can substantially increase their attractiveness to ants (Volkl et al., 1999; Madsen et al., 2017). Testing the attractiveness of different sugar concentrations, types of sugars and types of amino acids to wood ants may help to develop sugar solutions that can outcompete honeydew. In this way, we believe it is also possible to disrupt the wood ant-aphid mutualism. There is reason to believe that an optimized solution can outcompete honeydew, as there is already interspecific competition between aphids going on when it comes to ant attention. At the arrival of aphid species that produce superior honeydew, ants may neglect a previously otherwise attended aphid species because the latter now produce honeydew of inferior quality (compared to the honeydew from the new species) (Cushman \& Addicott, 1989; Tena et al., 2013).

Regarding nutrients, most leaf nutrients were unaffected by ant presence on the trees. However, we found increased levels of magnesium in the leaves of ant trees (Table 1, Figure 5). Magnesium content increased from approximately $0.18 \%$ to almost $0.19 \%$ dry weight of leaves. Both of these values are below the recommended level of 20\% (Gartnerirådgivningen, 2016), for which reason it is likely that the trees were limited by this nutrient. If this is the case and if ants were responsible for the observed increase, provisioning of nutrients could be another benefit resulting from ant attendance. However, more work is needed to uncover this potential service in more detail and to verify its cause. Strangely, magnesium was the only nutrient out of 11 that was affected. Whether ants in general increase levels of magnesium in their environment is interesting. Increased magnesium levels have been observed in nests of Atta laevigata, Solenopsis invicta and L. niger, on the other hand, lower levels have been observed in nests of Pogonomyrmes occidentalis (reviewed by Folgarait, 1998). If the observed effect was, indeed, caused by ants, it is most likely a result of the deposition of ant fecal spots on the foliage, as the ground below ant and control trees was equally accessible to the ants in the plantation. If nutrients were absorbed via the soil, no difference between treatments was expected. Uptake from foliage has been observed in weaver ants where nitrogen from their fecal spots was absorbed directly by coffee leaves (Pinkalski et al., 2018). Nitrogen, however, was not affected by ant presence in the current study.

Our study also found support for an ant-based plant pathogen defence, as we found lower levels of diseased apples on ant trees. Significant effects on brown rot were found on both of the two varieties that were infected with this disease (Alkmene and Collina), whereas a significant effect on apple scab was found on Holsteiner Cox. In the cases where we detected significance, the magnitude of the effects was several-fold ( $>2$-fold for brown rot and $>11$-fold for apple scab), whereas ants only lead to minor reductions of scab on Alkmene and Collina. Only on Resista did we find a weak non-significant trend in the opposite direction. This pattern may result from Resista being partly resistant to apple scab (the name Resista refers to apple scab resistance), seen by its lower infection rate compared to the other varieties (Figure 7). The lack of significant effects on apple scab on Alkmene and Collina could be a result of low sample sizes and/or the fact that these two varieties were highly infected, with $+40 \%$ of the apples carrying more than three apple scab spots. On these varieties, spot densities were high, which is why it requires more to reduce spot numbers to three spots or lower. The effects of ants may well have reduced spot numbers, but without being able to push numbers below three spots per apple. Unfortunately, we did not count the number of spots on apples, but only divided apples into categories with less or more than three spots. However, it should be noted that despite a reduced pathogen incidence, this did not lead to significant effects on apple yields. The current results on pathogens are highly interesting, but more work is needed to assess whether effects are applicable, i.e. can lead to higher yields. It would be worthwhile to test the effect of wood ants in crops that are more susceptible to these two diseases, e.g. cherries and plums, which are plagued by brown rot to a greater extent than apples.

Despite significant effects on plant pathogens, we do not know the mechanism(s) behind these effects. In the case 
of brown rot, the reduced incidence could result from ants deterring skin-damaging arthropods that would otherwise provide access points for infections. However, this fails to explain the reduced incidence of apple scab, as this fungus does not rely on skin damage to infect apples. Instead, ant excretions could be a possible mechanism. F. polyctena excrete formic acid for defence and prey killing, and they use mellein in their trail pheromones (Bestmann et al., 1992; Morgan, 2008). Both of these substances are known to possess antibiotic properties when applied in small dosages. Formic acid has been suggested to be prophylactically applied by $F$. polyctena on nest material to control bacterial pathogens (Sauerländer, 1961), and weaver ants control the entomopathogenic fungus Metarhizium with this compound (Tranter \& Hughes, 2015). Similarly, mellein serve as an antiseptic when released in small amounts from the metapleural gland of Crematogaster deformis (Attygalle et al., 1989; Morgan, 2008). Thus, it is likely that $F$. polyctena excrete antibiotic substances (either for defence/attack or to mark their trails) that may end up on plant tissue, where they could potentially reduce pathogen spore germination and/or growth. It is known that formic acid inhibits brown rot. In petri dish cultures, brown rot growth was inhibited when $45 \%$ formic acid or crushed weaver ants (containing formic acid) were applied to the growth medium (Zhang, 2017). In the plantation, we often observed $F$. polyctena spraying formic acid when disturbed. Whether the ants also release formic acid in smaller doses on host plants is unknown. Mellein, however, is likely to be deposited directly on apple trees when the ants use trail pheromones for navigation.

The ants clearly provided both services and disservices in the apple plantation. During the first year, this resulted in increased apple yields on trees with the highest ant abundance. In the second year, however, the net effect did not affect apple production. Possible explanations for this difference are unclear. In the second year, yields were more than 11 times higher than the low yield observed in 2015. It may be argued that ants are unable to increase yields during periods with high production, as there is no problem for the ants to fix in such periods. This could explain the lack of a positive effect in 2016. Alternatively, the lack of an effect in 2016 could be due to higher numbers of aphids on the trees and, therefore, a build-up in the disservice. Aphid densities were likely much higher in the second year, as the proportion of infected trees was $89 \%$ in 2016 compared to only $7 \%$ in 2015 . Unfortunately, we were unable to compare densities directly, as we did not count the numbers of colonies in 2015, but only whether trees were infected or not.

In conclusion, we found support for all proposed hypotheses: (i) that ants reduce herbivore abundance (winter moth larvae), (ii) fertilize host plants (magnesium), (iii) control apple pathogens (brown rot and apple scab), (iv) increase homopteran abundance (Aphis pomi) and that this (v) affects apple yields (in 2015). On the other hand, results are also inconclusive as (i) the net effect on yield was not consistent across years, and pathogen control was not consistent across apple varieties. This pinpoints that the current study must be considered a pilot study that needs spatial and temporal replication before we are able to recommend whether or not wood ants can be used in IPM approaches in fruit plantations. Yet again, we feel confident to conclude that wood ants, at least under some conditions, provide positive effects on apples and probably also on other fruit crops. Future studies may uncover whether ants should be used only temporarily during intense pest outbreaks in order to avoid a build-up of harmful homopterans, or whether wood ants are applicable in other crops that do not host ant-attended species. Furthermore, future studies should focus on the development of sugar baits that can outcompete honeydew to the detriment of the antaphid mutualism. This may open the possibility of using wood ants long term (prophylactically), even in crops that are vulnerable to ant-attended pests.

\section{Acknowledgement}

This study was supported by the GUDP/ICROFS Organic RDD 2.2 project MothStop (34009-15-0984).

\section{Authors' contributions}

J Offenberg drafted the manuscript and contributed to fieldwork, conception, design, and interpretation. JS Nielsen contributed to fieldwork and design and CF Damgaard performed the statistical analyses and contributed to interpretation and revisions of the manuscript. All authors have approved the final version of the manuscript.

\section{References}

Attygalle, A.B., Siegel, B., Vostrowsky, O., Bestmann, H.J. \& Maschwitz, U. (1989). Chemical composition and function of metapleural gland secretion of the ant, Crematogaster deformis Smith (Hymenoptera: Myrmicinae). Journal of Chemical Ecology, 15: 317-328. doi: 10.1007/bf02027793.

Bestmann, H.J., Kern, F., Schäfer, D. \& Witschel, M.C. (1992). 3,4-Dihydroisocoumarins, a New Class of Ant Trail Pheromones. Angewandte Chemie International Edition in English, 31: 795-796. doi: 10.1002/anie.199207951.

Cushman, J.H. \& Addicott, J.F. (1989). Intra- and interspecific competition for mutualists: ants as a limited and limiting resource for aphids. Oecologia, 79: 315-321. doi: 10.1007/ bf00384310.

Delabie, J.H.C. (2001). Trophobiosis Between Formicidae and Hemiptera (Sternorrhyncha and Auchenorrhyncha): an Overview. Neotropical Entomology, 30: 501-516. doi: 10.1590/S1519-566X2001000400001

Folgarait, P.J. (1998). Ant biodiversity and its relationship to ecosystem functioning: A review. Biodiversity and Conservation, 7: 1221-1244. doi: 10.1023/A:1008891901953. 
Frouz, J., Rybníček, M., Cudlín, P. \& Chmelíková, E. (2008). Influence of the wood ant, Formica polyctena, on soil nutrient and the spruce tree growth. Journal of Applied Entomology, 132, 281-284. doi: 10.1111/j.1439-0418.2008.01285.x.

Gartnerirådgivningen (2016). Håndbog for frugt- og bæravlere. Gartnerirådgivningen, Odense, Denmark.

Gonzalez-Teuber, M., Kaltenpoth, M. \& Boland, W. (2014). Mutualistic ants as an indirect defence against leaf pathogens. New Phytologist, 202, 640-650. doi: 10.1111/nph.12664.

Letourneau, D.K. (1998). Ants, stem-borers, and fungal pathogens: Experimental tests of a fitness advantage in Piper ant-plants. Ecology, 79, 593-603.

Madsen, N.E.L., Sorensen, P.B. \& Offenberg, J. (2017). Sugar and amino acid preference in the black garden ant Lasius niger (L.). Journal of Insect Physiology, 100: 140-145. doi: 10.1016/j.jinsphys.2017.05.011.

Morgan, E.D. (2008). Chemical sorcery for sociality: exocrine secretions of ants (Hymenoptera: Formicidae). Myrmecological News, 11: 79-90.

Nagy, C., Cross, J.V. \& Markó, V. (2013). Sugar feeding of the common black ant, Lasius niger (L.), as a possible indirect method for reducing aphid populations on apple by disturbing ant-aphid mutualism. Biological Control, 65: 24-36. doi: 10.1016/j.biocontrol.2013.01.005.

Nagy, C., Cross, J.V. \& Markó, V. (2015). Can artificial nectaries outcompete aphids in ant-aphid mutualism? Applying artificial sugar sources for ants to support better biological control of rosy apple aphid, Dysaphis plantaginea Passerini in apple orchards. Crop Protection, 77: 127-138. doi: 10.1016/j. cropro.2015.07.015.

Nielsen, J.S., Nielsen, M.G., Damgaard, C. \& Offenberg, J. (2018). Experiences in transplanting wood ants into plantations for integrated pest management. Sociobiology, 65: 403-414. doi: 10.13102/sociobiology.v65i3.2872.

Offenberg, J. (2001). Balancing between mutualism and exploitation: the symbiotic interaction between Lasius ants and aphids. Behavioral Ecology and Sociobiology, 49, 304310. doi: $10.1007 / \mathrm{s} 002650000303$.

Offenberg, J. (2014). Pest repelling properties of ant pheromones. IOBC-WPRS Bulletin, 99, 173-176. doi:

Offenberg, J. (2015). Ants as tools in sustainable agriculture. Journal of Applied Ecology, 52, 1197-1205. doi: 10.1111/ 1365-2664.12496.

Peng, R.K. \& Christian, K. (2005). Integrated pest management in mango orchards in the Northern Territory Australia, using the weaver ant, Oecophylla smaragdina, (Hymenoptera : Formicidae) as a key element. International Journal of Pest Management, 51: 149-155. doi: 10.1080/09670870500131749.
Pinkalski, C., Jensen, K.-M.V., Damgaard, C. \& Offenberg, J. (2018). Foliar uptake of nitrogen from ant faecal droplets: An overlooked service to ant-plants. Journal of Ecology, 106: 289-295. doi: 10.1111/1365-2745.12841.

Rico-Gray, V. \& Oliveira, P.S. (2007). The Ecology and Evolution of Ant-Plant Interactions. The University of Chicago Press, USA.

Roux, O., Céréghino, R., Solano, P.J. \& Dejean, A. (2011). Caterpillars and Fungal Pathogens: Two Co-Occurring Parasites of an Ant-Plant Mutualism. PLoS ONE, 6: e20538. doi: 10.1371/journal.pone.0020538.

Rue, H., Martino, S. \& Chopin, N. (2009). Approximate Bayesian inference for latent Gaussian models by using integrated nested Laplace approximations. Journal of the Royal Statistical Society: Series B (Statistical Methodology), 71: 319-392. doi: 10.1111/j.1467-9868.2008.00700.x.

Sauerländer, S. (1961). Das Gift von Formica polyctena FÖRST. als ein möglicher Schutzmechanismus dieses Insekts gegen Mikroorganismen. Die Naturwissenshaften, 48: 629.

Skinner, G.J. \& Whittaker, J.B. (1981). An experimental investigation of interrelationships between the wood ant (Formica rufa) and some treew canopy herbivores. Journal of Animal Ecology, 50: 313-326. doi: 10.2307/4047.

Tena, A., Hoddle, C.D. \& Hoddle, M.S. (2013). Competition between honeydew producers in an ant-hemipteran interaction may enhance biological control of an invasive pest. Bulletin of Entomological Research, 103: 714-723. doi: 10.1017/ S000748531300045X.

Thornham, D., G., Smith, J., M., Ulmar, G., T. \& Federle, W. (2011). Setting the trap: cleaning behaviour of Camponotus schmitzi ants increases long-term capture efficiency of their pitcher plant host, Nepenthes bicalcarata. Functional Ecology, 26: 11-19. doi: 10.1111/j.1365-2435.2011.01937.x.

Tranter, C. \& Hughes, W.O.H. (2015). Acid, silk and grooming: alternative strategies in social immunity in ants? Behavioral Ecology and Sociobiology, 69: 1687-1699. doi: 10.1007/ s00265-015-1980-3.

Vidkjær, N.H., Wollenweber, B., Jensen, K.M.V., Ambus, P.L., Offenberg, J. \& Fomsgaard, I.S. (2016). Urea in Weaver Ant Feces: Quantification and Investigation of the Uptake and Translocation of Urea in Coffea arabica. Journal of Plant Growth Regulation, 35: 803-814. doi: 10.1007/s00344-016-9586-1.

Volkl, W., Woodring, J., Fischer, M., Lorenz, M.W. \& Hoffmann, K.H. (1999). Ant-aphid mutualisms: the impact of honeydew production and honeydew sugar composition on ant preferences. Oecologia, 118: 483-491.

Wagner, D. \& Fleur Nicklen, E. (2010). Ant nest location, soil nutrients and nutrient uptake by ant-associated plants: Does extrafloral nectar attract ant nests and thereby enhance 
plant nutrition? Journal of Ecology, 98: 614-624. doi: 10.11 11/j.1365-2745.2010.01640.x.

Way, M.J. (1954). Studies on the association of the ant Oecophylla longinoda (Latr) (Formicidae) with the scale insect Saissetia zanzibarensis Williams (Coccidae). Bulletin of Entomological Research, 45: 113-134.

Way, M.J. \& Khoo, K.C. (1992). Role of ants in pestmanagement. Annu Rev Entomol, 37: 479-503.
Wäckers, F.L., Alberola, J.S., Garcia-Mari, F. \& Pekas, A. (2017). Attract and distract: Manipulation of a foodmediated protective mutualism enhances natural pest control. Agriculture, Ecosystems and Environment, 246: 168-174. doi: 10.1016/j.agee.2017.05.037.

Zhang, Y. (2017). The antimicrobial activities of Oecophylla smaragdina. Master degree Master Thesis, Aarhus University.

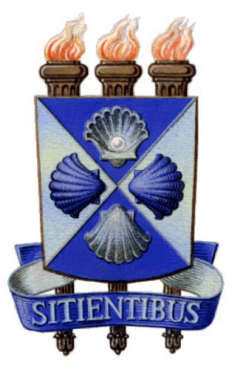

